\title{
Effects of Positional Overlap on Interactions and Co-occurrence of Follower Fishes in Benthic Foraging Associations
}

\author{
Genady Filkovsky* and William W. Hoback \\ University of Nebraska Kearney, Biology Department, 905 W 25 $5^{\text {th }}$ St., Kearney, NE 68849, USA
}

\begin{abstract}
Opportunistic predatory reef fishes commonly follow foraging benthivores to feed on prey disturbed by the benthivores. This study examined factors that may restrict the number and the species composition of follower fishes. Association groups common on the reefs around Bonaire were followed and videotaped. The follower compositions and interactions were quantified. Time spent by the followers in different positions around the nuclear benthivore was calculated. Follower species occupied some positions more often than others, and the preferred positions were speciesspecific. A high degree of overlap in these positions corresponded to repelling interactions between followers and to the absence of their co-occurrence in the associations. A low degree of the positional overlap corresponded to the absence of repelling interactions and to co-occurrence of the followers in the same association.
\end{abstract}

Keywords: Follower relations, nuclear benthivore, repelling interactions, species composition, behaviour.

\section{INTRODUCTION}

Many opportunistic predatory reef fishes spend significant time following benthic carnivores and feeding on prey disturbed by the foraging activities of these species [1,2]. Such benthic foraging associations are a common phenomenon and are considered an important factor in reef ecology [1-5]. Previous studies of these associations focused mainly on description and investigation of nuclear-follower relations [1-28]. Interactions between followers were noted $[4,6-11,29]$, but relations between followers and their effect on the followers' individual and species composition in the associations were not specifically studied.

It was noted in the literature and also observed by the author (GF) that followers of some species repel each other and apparently prevent con-specific and some hetero-specific assemblages while other followers appear mutually indifferent and commonly co-occur in the associations. This study aimed to find factors that may explain these differences. Previous studies $[9,10]$ suggested that followers seek to maintain an advantageous position near the nuclear benthivore and repel others from this location. During observations of reef fish, species following a benthivore appeared to be non-random. Thus, we hypothesized that followers in benthic foraging associations occupy speciesspecific positions relative to the nuclear benthivore, and that followers repel each other if their preferential positions overlap but are indifferent otherwise.

\section{MATERIALS AND METHODS}

To test the hypothesis that followers in a benthic foraging association occupy different positions, data were collected during 30 SCUBA dives lasting approximately 35 hours

*Address correspondence to this author at the Biology Department, University of Nebraska Kearney, $905 \mathrm{~W}$ 25th Street, Kearney, Nebraska 68849-1140, USA; Tel: +599-717-4593; E-mail: lagoenhill20@yahoo.com made by GF between May 2007 and October 2009 on the leeward reefs of Bonaire and around Klein Bonaire, Lesser Antilles $\left(12^{\circ} \mathrm{N}, 68^{\circ} \mathrm{W}\right)$. The area of study was a shallow reef-flat (4-10 m depth) covered with sand, coral rubble, and patches of live corals and gorgonians. The dives were made at various daytime hours, at various sites separated by $0.1-5.0 \mathrm{~km}$.

The common nuclear benthivores in the study area were spotted goatfish Pseudupeneus maculatus (Bloch) and yellow goatfish Mulloidichthys martinicus (Cuvier) [29]. Their common followers were bar jack Caranx ruber (Bloch), yellowhead wrasse Halichoeres garnoti (Valenciennes), and Spanish hogfish Bodianus rufus (Linnaeus) [29]. Nuclear $P$. maculatus were observed mostly foraging singly while nuclear M. martinicus foraged both singly and in groups of up to dozens individuals. For consistency, only foraging associations with a single nuclear $P$. maculatus or $M$. martinicus and with the followers being $H$. garnoti, B. rufus, or $C$. ruber, were used in this study.

Observed associations were followed at a distance of 2-3 $\mathrm{m}$ and video recorded using a Sony DCR-HC20 digital video camera in Ewa-Marine aqua-housing. For analysis, snapshots were taken every 10 seconds from the video recordings and then used to calculate the followers' time spent in different positions in the associations. To determine significant interactions, benthic follower associations were analyzed using Chi-squared Goodness of Fit tests $(\mathrm{P}<0.05)$ for single followers and followers observed in pairs.

\section{RESULTS}

A total of 70 benthic follower associations were observed. In 28 of them a nuclear benthivore was followed by a single $H$. garnoti, in 19 - by a single $B$. rufus, and in 14 - by a single $C$. ruber. An individual $C$. ruber with an individual $B$. rufus were observed in six of the associations, and an individual $C$. ruber with an individual $H$. garnoti were observed three times. No con-specific followers were 

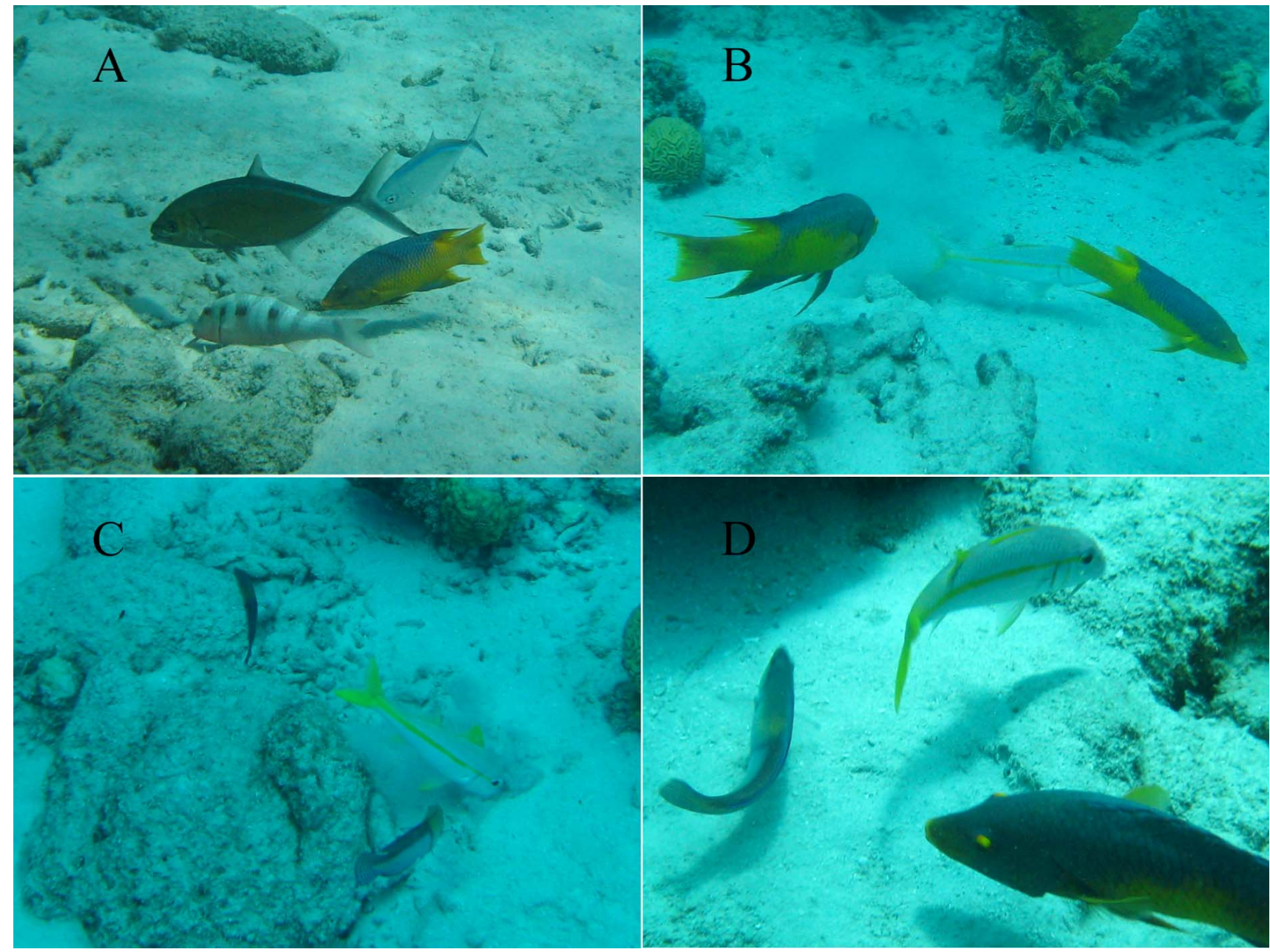

Fig. (1). Repelling interactions between followers. (A) A smaller C. ruber waits to replace a larger C. ruber in an association of $C$. ruber and $B$. rufus following a nuclear $P$. maculatus. (B) A larger B. rufus chases away and replaces a smaller $B$. rufus in the association with a nuclear M. martinicus. (C) A smaller H. garnoti replaces a larger H. garnoti after the latter leaves the association with a nuclear M. martinicus. (D) $B$. rufus chases away and replaces $H$. garnoti in the association with a nuclear M. martinicus.

observed in an association, nor were B. rufus observed with H. garnoti in the same association.

While observing associations where C. ruber were followers, other individuals of $C$. ruber were seen to approach the associations. These approaches always led to repelling interactions in which an established following $C$. ruber either chased away an approaching one, a newcomer replaced the resident individual, or an individual C. ruber followed the association at a distance and replaced the resident individual as soon as the latter left (Fig. 1A). Such interactions occurred during all 23 observed associations with $C$. ruber.

While observing 6 of 25 associations where B. rufus were followers, other individuals of $B$. rufus were seen to approach the associations. In all these cases either the resident individual $B$. rufus repelled the newcomer or the resident was replaced by the newcomer (Fig. 1B). Individuals of $H$. garnoti were observed approaching and having the same repelling interactions with the resident individual $H$. garnoti during 6 of 31 associations in which $H$. garnoti were followers (Fig. 1C). In 9 associations, B. rufus and $H$. garnoti individuals were observed to approach a nuclear benthivore and have repelling interactions between themselves. These interactions involved a newcomer individual $B$. rufus chasing away and replacing the resident individual $H$. garnoti (Fig. 1D), a resident $B$. rufus chasing away an approaching individual $H$. garnoti, and individual $H$. garnoti following an association at a distance and replacing the resident $B$. rufus as soon as it left. No repelling interactions were observed between $C$. ruber and B. rufus or between $C$. ruber and $H$. garnoti.

The followers C. ruber were recorded for a total of 10.3 hours in 17 dives, $H$. garnoti - for a total of 3.8 hours in 18 dives, and B. rufus - for a total of 2.1 hours in 19 dives. Positions of the followers were categorized as front, behind, right, left, and above according to the position of their head relative to the nuclear benthivore (Fig. 2, Table 1). Analysis of the times spent in different positions showed significant differences for each follower (Table 2). The distribution of the position usage also significantly differed between the followers (Table 3). The follower C. ruber strongly preferred the position above the nuclear benthivore, while both $H$. garnoti and B. rufus preferred positions behind it (Fig. 3). 

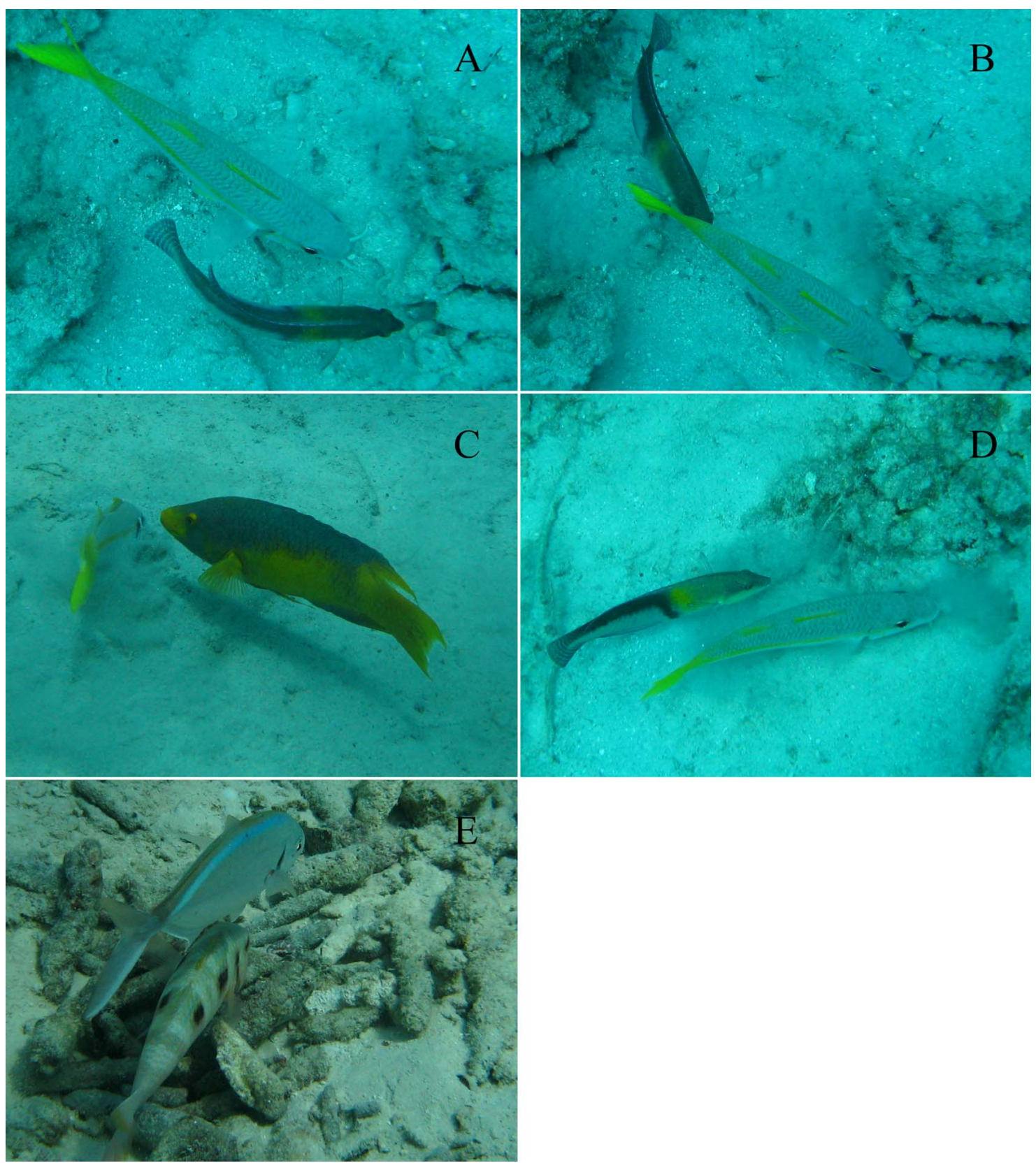

Fig. (2). Follower positions in the associations (A) in front, (B) behind, (C) right, (D) left, and (E) above a nuclear benthivore.

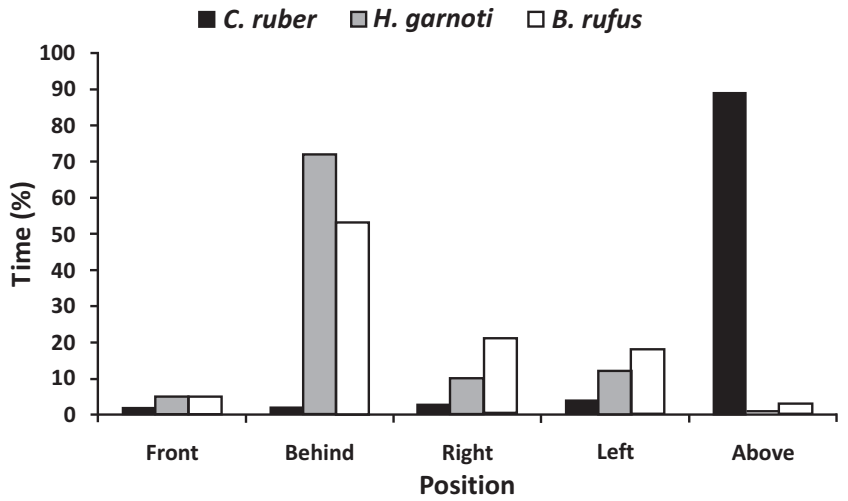

Fig. (3). Percentage time spent by the follower species in different positions relative to the nuclear benthivore.
Table 1. Number of Snap-Shots of Follower Species in Different Positions Relative to the Nuclear Benthivore $H G=$ H. garnoti, $B R=B$. rufus, $C R=C$. rubber

\begin{tabular}{|c|c|c|c|c|c|c|c|c|}
\hline \multirow[t]{2}{*}{ Followers } & \multirow{2}{*}{$\begin{array}{c}\text { Observed } \\
\text { association } \\
\text { numbers }\end{array}$} & \multirow{2}{*}{$\begin{array}{c}\text { Observation } \\
\text { time (hrs) }\end{array}$} & \multicolumn{6}{|c|}{$\begin{array}{c}\text { Position of followers in snap-shot } \\
\text { numbers }\end{array}$} \\
\hline & & & & Front & Behind & Right & Left & Above \\
\hline $1 \mathrm{HG}$ & 28 & 3.7 & & 62 & 981 & 134 & 165 & 7 \\
\hline $1 \mathrm{BR}$ & 19 & 1.9 & & 25 & 388 & 135 & 112 & 3 \\
\hline $1 \mathrm{CR}$ & 14 & 10.0 & & 87 & 74 & 118 & 123 & 3,194 \\
\hline \multirow{2}{*}{$\begin{array}{c}1 \mathrm{CR}+1 \\
\mathrm{BR}\end{array}$} & \multirow{2}{*}{6} & \multirow{2}{*}{0.2} & $C R$ & 2 & 2 & 7 & 5 & 69 \\
\hline & & & $B R$ & 12 & 22 & 22 & 25 & 4 \\
\hline \multirow{2}{*}{$\begin{array}{c}1 \mathrm{CR}+1 \\
\mathrm{HG}\end{array}$} & \multirow{2}{*}{3} & \multirow{2}{*}{0.1} & $C R$ & 1 & 1 & 4 & 3 & 26 \\
\hline & & & $H G$ & 6 & 16 & 7 & 6 & 0 \\
\hline Total & 70 & 15.9 & & 195 & 1,484 & 427 & 439 & 3,303 \\
\hline
\end{tabular}


Table 2. Test of Preferential Positions by a Follower $H G=$ H. garnoti, $B R=B$. rufus, $C R=C$. rubber

\begin{tabular}{|c|c|c|c|}
\hline Follower & Number of snap-shots & Chi-square & P \\
\hline \hline CR alone & 3596 & 10,647 & $<0.001$ \\
\hline CR in CR+BR pair & 85 & 200 & $<0.001$ \\
\hline CR in CR+HG pair & 35 & 65 & $<0.001$ \\
\hline BR alone & 663 & 709 & $<0.001$ \\
\hline BR in CR+BR pair & 85 & 18 & $<0.005$ \\
\hline HG alone & 1,349 & 2,400 & $<0.001$ \\
\hline HG in CR+HG pair & 35 & 19 & $<0.001$ \\
\hline
\end{tabular}

Table 3. Pairwise Comparisons of Position Distributions between Followers

$H G=$ H. garnoti, $B R=B$. rufus, $C R=C$. rubber

\begin{tabular}{|c|c|c|}
\hline Follower combination & $\begin{array}{c}\text { Chi- } \\
\text { square }\end{array}$ & P \\
\hline \hline CR alone/ BR alone & 2,691 & $<0.001$ \\
\hline CR alone/ BR in CR+BR pairs & 542 & $<0.001$ \\
\hline CR in CR+BR pairs/ BR alone & 568 & $<0.001$ \\
\hline CR in CR+Br pairs/ BR in CR+BR pairs & 103 & $<0.001$ \\
\hline CR alone/ HG alone & 3,709 & $<0.001$ \\
\hline CR alone/ HG in CR+HG pairs & 373 & $<0.001$ \\
\hline CR in CR+HG pairs/ HG alone & 803 & $<0.001$ \\
\hline CR in CR+HG pairs/ HG in CR+HG & 45 & $<0.001$ \\
\hline pairs & 57 & $<0.001$ \\
\hline BR alone/ HG alone & 14 & $<0.01$ \\
\hline BR alone/ HG in CR+HG pairs & 94 & $<0.001$ \\
\hline BR in CR+BR pairs/ HG alone & n/a & cannot be \\
\hline BR in CR+BR pairs/ HG in CR+HG pairs & \\
\hline
\end{tabular}

The positional overlaps in the three con-specific follower pairs and that of B. rufus with $H$. garnoti were high, while positional overlap of $C$. ruber with $B$. rufus and that of $C$.

Table 4. Overlap of the Preferential Positions, Observation of Repelling Interactions and of Co-Occurrences of the Follower Pairs in Benthic Foraging Associations

\begin{tabular}{|c|c|c|c|}
\hline Follower pair & $\begin{array}{c}\text { Positional } \\
\text { preferences }\end{array}$ & $\begin{array}{c}\text { Repelling } \\
\text { interactions }\end{array}$ & $\begin{array}{c}\text { Co- } \\
\text { occurrences }\end{array}$ \\
\hline \hline C. ruber / C. ruber & Above/ Above & Yes & No \\
\hline $\begin{array}{c}\text { H. garnoti / } \\
\text { H. garnoti }\end{array}$ & Behind / Behind & Yes & No \\
\hline B. rufus / B. rufus & Behind / Behind & Yes & No \\
\hline B. rufus / H. garnoti & Behind / Behind & Yes & No \\
\hline B. rufus / C. ruber & Behind / Above & No & Yes \\
\hline $\begin{array}{c}\text { H. garnoti / } \\
\text { C. ruber }\end{array}$ & Behind / Above & No & Yes \\
\hline
\end{tabular}

ruber with $H$. garnoti were low (Table 4). The co-occurrence of followers in the associations and the repelling interactions between them corresponded to the preference of their positions. Individuals of four species-pairs with highly overlapping positions displayed repelling interactions every time two of them were observed near the nuclear benthivore, and they were not observed to co-occur in associations (Table 4). The followers of two species-pairs with low positional overlap did not display repelling interactions and were observed in the same associations (Table 4).

\section{DISCUSSION}

A high degree of overlap in preferred positions in benthic followers is likely to lead to conflict because two followers cannot occupy the same position at the same time. This conflict may cause repelling interactions between the followers and act as a restricting factor on individual followers' number and species composition. Thus, a high degree of positional overlap can be used to predict followers that repel each other and that do not or only rarely co-occur in foraging associations.

Any follower with a strong positional preference has a high degree of positional overlap with its con-specifics. Consequently, frequent repelling interactions between conspecific followers are predicted and were supported by the observed repelling interactions between con-specific followers in this study. Previously, con-specific repulsion of followers has been observed with Bodianus diplotaenia (Gill) in the Gulf of California [4], Ocyurus chrysurus (Bloch) on the Atlantic coast of Panama [6], C. ruber in Belize [7], Pseudolabrus eoethinus (Richardson) and $P$. sieboldi (Mabuchi and Nakabo) near the southern coast of Japan [8], Thalassoma pavo (Linnaeus) and Diplodus sargus cadenati (de la Paz, Bauchot \& Daget) in the Azores [9], and Epinephelus marginatus (Lowe) off the coast of Southern Brazil [10]. For the same reason, it can be predicted that associations with multiple species of followers will show repulsion when the following species have the same positional preferences, as was documented in this study.

Positional preferences may result from a multitude of factors including the follower's diet, morphology, predatory behavior, and foraging tactics. In this paper we documented assemblages of two nuclear benthivorous predators with three common followers and found that mutual exclusion occurred most often between con-specifics and between species of the same family, Labridae. Of the follower species, $C$. ruber spent the majority of its time above the nuclear individual, while $H$. garnoti and $B$. rufus spent most of their time in the position behind the nuclear individual. Based on these observations, multi-species assemblages can frequently occur between $C$. ruber and the other species, but will be limited between $H$. garnoti and B. rufus. Additional research in areas where these species occur singly and in mixed populations is warranted to better elucidate competition and co-existence.

\section{ACKNOWLEDGEMENT}

None declared. 


\section{CONFLICT OF INTEREST}

None declared.

\section{REFERENCES}

[1] Lukoshcek V, McCormick MI. A review of multi-species foraging associations in fishes and their ecological significance. Proceedings of the 9th International Coral Reef Symposium; 2000 Oct 23-27; Bali, Indonesia; 2002; pp. 467-74.

[2] Sazima C, Krajewski P, Bonaldo RM, Sazima I. Nuclear-follower foraging associations of reef fishes and other animals at an oceanic archipelago. Environ Biol Fish 2007; 80: 351-61.

[3] Ormond RFG. Aggressive mimicry and other interspecific feeding associations among Red Sea coral reef predators. J Zool 1980; 191: 247-62.

[4] Strand S. Following behavior: interspecific foraging associations among Gulf of California reef fishes. Copeia 1988; 1988: 351-7.

[5] Sazima C, Krajewski JP, Bonaldo RM, Guimaraes PR Jr. The goatfish Pseudupeneus maculatus and its follower fishes at an oceanic island in the tropical west Atlantic. J Fish Biol 2006; 69: 883-91.

[6] Sikkel PC. Interspecific feeding associations between the goatfish Mulloides martinicus (Mullidae) and a possible aggressive mimic, the snapper Ocyurus chrysurus (Lutjanidae). Copeia 1992; 1992: 914-7.

[7] Baird TA. A new heterospecific foraging association between the pudding wrasse, Halochoeres radiates, and the bar jack, Caranx ruber: evaluation of the foraging consequences. Environ Biol Fish 1993; 38: 393-7.

[8] Matsumoto K, Kohda M, Yanagisawa Y. Size-dependent feeding association of two wrasses (genus Pseudolabrus) with the morwong, Goniistius zonatus. Ichthyol Res 1999; 46: 57-65.

[9] Soares MSC, Barreiros JP. Following associations with the striped red mullet Mullus surmuletus Linnaeus, 1758 (Perciformes: Mullidae) from the Azores. J Ichthyol Aquat Biol 2003; 7: 139-44.

[10] Gerhardinger LC, Hostim-Silva M, Samagaia R, Barreiros JP. A following association between juvenile Epinephelus marginatus (Serranidae) and Myrichthys ocellatus (Ophichthidae). Cybium 2006; 30: 82-4.

[11] Craig MT, Erisman BE. A competitive following association between two reef fishes and the jewelled moray in the Gulf of California, Mexico. Coral Reefs 2010; 29: 813.

[12] Karplus I. A feeding association between the grouper Epinephelus fasciatus and the moray eel Gymnothorax griseus. Copeia 1978; 1978: 164

[13] Dubin RE. Behavioral interactions between Caribbean reef fish and eels (Muraenidae and Ophichthidae). Copeia 1982; 1982: 229-32.
[14] Diamant A, Shpigel M. Interspecific feeding associations of groupers (Teleostei: Serranidae) with octopuses and moray eels in the Gulf of Eilat (Aqaba). Environ Biol Fish 1985; 13: 153-9.

[15] Aronson RB, Sanderson SL. Benefits of heterospecific foraging by the Caribbean wrasse, Halichoeres garnoti (Pisces: Labridae). Environ Biol Fish 1987; 18: 303-8.

[16] Mather JA. Interactions of juvenile Octopus vulgaris with scavenging and territorial fishes. Mar Behav Physiol 1992; 19: 17582.

[17] Spotte S. Habitat and temporal effects on diurnal, mixed-species foraging associations of the yellow goatfish (Mulloidichthys martinicus) at Arise Chastanet, St. Lucia, West Indies. Caribb J Sci 1996; 32: 21-5.

[18] Silvano RAM. Feeding habits and interspecific feeding associations of Caranx latus (Carangidae) in a subtropical reef. Environ Biol Fish 2001; 60: 465-70.

[19] Gibran FZ. The sea basses Diplectrum formosum and D. radiale (Serranidae) as followers of the sea star Luidia senegalensis (Asteroidea) in Southern Brazil. Braz J Biol 2002; 62: 591-4.

[20] Sazima C, Grossman A, Bellini C, Sazima I. The moving garden: reef fishes grazing, cleaning, and following green turtles in SW Atlantic. Cybium 2004; 28: 47-56.

[21] Sazima C, Bonaldo RM, Krajewski JP, Sazima I. The noronha wrasse: a "jack-of-all-trades" follower. Aqua 2005; 9: 97-108.

[22] Sazima C, Grossman A. A non-digging zoobenthivorous fish attracts two opportunistic predatory fish associates. Neotrop Ichthyol 2005; 3: 445-8.

[23] Bshary R, Hohner A, Ait-el-Djoudi K, Fricke H. Interspecific communicative and coordinated hunting between groupers and giant moray eels in the Red Sea. PLoS Biol 2006; 4: e431.

[24] Krajewski JP, Bonaldo RM, Sazima C, Sazima I. Foraging activity and behavior of two goatfish species (Perciformes: Mullidae) at Fernando de Noronha Archipelago, tropical West Atlantic. Environ Biol Fish 2006; 77: 1-8.

[25] Maia-Nogueira R, Nunes JACC, Coni EOC, Ferreire CM, Sampaio CLS. The twinspot bass Serranus flaviventris (Serranidae) as follower of the goldspotted eel Myrichthys ocellatus (Ophichthidae) in north-eastern Brazil, with notes on other serranids. Mar Biodivers Rec 2009; 2: e99.

[26] Felix FC, Hackradt CW. Interaction between Rachycentron canadum and Epinephelus itajara, on the Parana Coast, Brazil. Coral Reefs 2008; 27: 633.

[27] Araújo ME, Pereira PHC, Feitosa JLL, Gondolo G, Pimenta D, Nottingham MC. Feeding behavior and follower fishes of Myrichthys ocellatus (Anguilliformes: Ophichthidae) in the western Atlantic. Neotrop Ichthyol 2009; 7: 503-7.

[28] Krajewski JP. How do follower reef fishes find nuclear fishes? Environ Biol Fish 2009; 86: 379-87.

[29] Auster PJ, Lindholm J. Pattern in the local diversity of coral reef fishes versus rates of social foraging. Caribb J Sci 2002; 38: 263-6.

(C) Filkovsky and Hoback; Licensee Bentham Open.

This is an open access article licensed under the terms of the Creative Commons Attribution Non-Commercial License (http://creativecommons.org/licenses/by$\mathrm{nc} / 3.0 /$ ), which permits unrestricted, non-commercial use, distribution and reproduction in any medium, provided the work is properly cited. 